\title{
FUNGOS MICORRÍZICOS ARBUSCULARES E PROTEÍNA DO SOLO RELACIONADA À GLOMALINA EM ÁREA DEGRADADA POR EXTRAÇÃO DE ARGILA E REVEGETADA COM EUCALIPTO E ACÁCIA
}

\author{
ARBUSCULAR MYCORRHIZAL FUNGI AND GLOMALIN-SOIL RELATED PROTEIN IN \\ DEGRADED AREAS AND REVEGETATED WITH EUCALYPT AND WATTLE \\ Cristiane Figueira da Silva ${ }^{1}$ Jean Luiz Simões-Araújo ${ }^{2}$ Eliane Maria Ribeiro da Silva ${ }^{3}$ \\ Marcos Gervasio Pereira ${ }^{4}$ Marta Simone Mendonça Freitas ${ }^{5}$ \\ Orivaldo José Saggin Júnior ${ }^{6}$ Marco Antônio Martins ${ }^{7}$
}

\begin{abstract}
RESUMO
Esse estudo teve como objetivo avaliar a influência da revegetação com Eucalyptus camaldulensis e Acacia mangium, em plantio puro e consorciado, na composição e diversidade de fungos micorrízicos arbusculares (FMAs), bem como na quantidade da proteína do solo relacionada à glomalina (PSRG) em uma área degradada pela extração de argila. O delineamento experimental utilizado foi o de blocos casualizados com quatro tratamentos (plantios puros de Eucalyptus camaldulensis e Acacia mangium; consórcio de Eucalyptus camaldulensis + Acacia mangium; e área degradada com vegetação espontânea - ADVE) e três repetições, onde, em cada uma das parcelas, foram coletadas amostras de solo na camada 0-5 cm. Os esporos de FMA foram extraídos e taxonomicamente identificados. Analisou-se a densidade relativa, a frequência de cada espécie e os índices de Shannon-Wiener, Pielou e de Simpson. A PSRG (glomalina total - GT e glomalina facilmente extraível - GFE) foi extraída com citrato de sódio e quantificada pelo método de Bradford. A abundância de FMAs foi maior na área degradada com vegetação espontânea quando comparada aos plantios, em contrapartida apresentou baixa diversidade de espécies. As áreas de eucalipto em monocultivo mostraram menor índice de diversidade de FMAs em relação às áreas de eucalipto consorciadas com a acácia. Glomus e Acaulospora foram os gêneros de FMAs que apresentaram o maior número de espécies. A PSRG foi estreitamente correlacionada com o $\mathrm{C}$ e o $\mathrm{N}$ do solo, tendo sido observada em maiores quantidades nos plantios, em relação à ADVE. A revegetação da cava de extração de argila promoveu redução na esporulação dos FMAs, enquanto a diversidade e a quantidade de PSRG foram aumentadas.
\end{abstract}

Palavras-chave: Eucalyptus camaldulensis; diversidade; microrganismos.

\footnotetext{
ABSTRACT

The objective of this study was to evaluate the influence of revegetation with Eucalyptus camaldulensis and Acacia mangium in pure and mixed stands in the composition and mycorrhizal fungi diversity (AMF), as

1. Engenheira Florestal, Dra ${ }^{\mathrm{a}}$, Pós-Doutoranda do curso de Pós-Graduação em Agronomia-Ciência do Solo, Universidade Federal Rural do Rio de Janeiro, BR 465 km 7, CEP 23890-000, Seropédica (RJ). Bolsista CNPq. cfigueirasilva@yahoo.com.br

2. Engenheiro Agrônomo, Dr., Pesquisador da Embrapa Agrobiologia, BR 465, km 7, CEP 23890-000, Seropédica (RJ).jean@cnpab.embrapa.br

3. Engenheira Florestal, Dra ${ }^{\mathrm{a}}$, Pesquisadora da Embrapa Agrobiologia, BR 465, km 7, CEP 23890-000, Seropédica (RJ). eliane@cnpab.embrapa.br

4. Engenheiro Agrônomo, Dr., Professor Adjunto do Departamento de Solos, Universidade Federal Rural do Rio de Janeiro, BR 465 km 7, CEP 23890-000, Seropédica (RJ). gervasio@ufrrj.br.

5. Graduada em Ciências, Dra, Professora Associada da Universidade Estadual do Norte Fluminense Darcy Ribeiro, Av. Alberto Lamego, 2.000, CEP 28013-602, Campos dos Goytacazes (RJ). msimone@uenf.br

6. Engenheiro Agrônomo, Dr., Pesquisador da Embrapa Agrobiologia, BR 465, km 7, CEP 23890-000, Seropédica $(\mathrm{RJ})$.

7. Engenheiro Agrônomo, PhD., Professor Titular da Universidade Estadual do Norte Fluminense Darcy Ribeiro, Av. Alberto Lamego, 2.000, Campos dos Goytacazes, RJ, CEP: 28013-602,marco@uenf.br

Recebido para publicação em 29/11/2010 e aceito em 10/08/2011
} 
well as in the production of glomalin-related soil protein (GRSP) of an area degraded by clay extraction. The experimental design used was randomized complete block with four treatments (pure stands Eucalyptus camaldulensis and Acacia mangium; mixed Eucalyptus camaldulensis + Acacia mangium; and covered with spontaneous vegetation - ADVE) and three replications. Soil samples were collected at $0-5 \mathrm{~cm}$ soil layer in each plot. The spores were extracted and taxonomically identified. Relative density, frequency of each species and the Shannon-Wiener, Pielou and Simpson indexes were analyzed. The GRSP (total glomalin - TG and easily extractable glomalin - EEG) was extracted with sodium citrate and quantified by the Bradford method. Abundance of AMF was higher in the degraded areas covered by weeds (spontaneous vegetation) compared to plantations; however, it showed lower species diversity. The areas of eucalypt monoculture showed a lower level of AMF diversity in relation to areas of eucalypt intercropped with Acacia. The genera Glomus and Acaulospora were the AMF, with the largest number of species. The GRSP was closely correlated with soil $\mathrm{C}$ and $\mathrm{N}$, which observed in greater amounts in plantations in relation to the sites covered with spontaneous vegetation. Revegetation of clay extraction site promoted the reduction of AMF sporulation, while the diversity and amount GRSP increased.

Keywords: Eucalyptus camaldulensis; diversity; microorganisms.

\section{INTRODUÇÃO}

Em Campos dos Goytacazes-RJ, a extração de argila para produção de telhas e tijolos assumiu um papel importante na geração de renda, após o declínio da atividade canavieira. Contudo, essa atividade tem provocado a degradação do solo, visto que, o processo envolve a retirada da vegetação pré-existente, seguida dos horizontes superficiais e subsuperficiais, originando cavas profundas. A retirada da vegetação natural e a intensa movimentação do solo promovem modificações físicas, químicas e biológicas no sistema (BATISTA et al. 2009; CUNHA et al., 2003; PAULUCIO, 2007) o que compromete a qualidade do solo, a microbiota edáfica e o processo de regeneração natural das espécies nativas (SILVA et al., 2010).

Algumas dessas áreas estão sendo revegetadas com plantios puros e consorciados de essências florestais comerciais e leguminosas (MENDONÇA et al., 2008; SCHIAVO et al., 2010), tendo em vista que a serapilheira depositada na superfície do solo por essas espécies, pode ter uma influência significativa nos atributos do solo, melhorando a sua qualidade.

Diversos estudos têm mostrado que a introdução de espécies arbóreas (leguminosas ou não) em áreas degradadas pode influenciar a população de fungos micorrízicos arbusculares (FMAs) afetando o número de esporos e a diversidade de espécies desses fungos (BATISTA et al., 2009; FRANCO et al., 1995; MELLONI et al., 2003; PAULUCIO, 2007). Caproni et al. (2005) observaram que a introdução de Acacia mangium em áreas degradadas pela mineração de bauxita, promoveu uma alta densidade de esporos, tendo esse aumentado em função da idade do plantio. Gould et al. (1996), estudando os FMAs em uma área minerada e revegetada, observaram que a densidade de propágulos de FMAs e a colonização de raízes das plantas introduzidas foram baixas no primeiro ano. Contudo, no segundo ano, a densidade de esporos e outros propágulos aumentaram, estabilizando-se nos anos seguintes com a sucessão vegetal. Caproni et al. (2003), em áreas mineradas e revegetadas com espécies nativas e exóticas, observaram que tanto a densidade quanto o número de espécies de FMAs. apresentaram valores significativamente maiores em relação à área não revegetada.

Na literatura, existem alguns relatos a respeito de fatores que podem influenciar a esporulação, a taxa de colonização e a diversidade de FMAs (CAPRONI et al., 2003; CAPRONI et al., 2007; LOSS et al., 2009; SILVA et al., 2007; SILVA et al., 2008). Características edáficas, espécies de plantas, cobertura vegetal desde a época de revegetação, condições ambientais e manejo, são sugeridos como fatores que interferem nas populações dos FMAs (EOM et al., 2000; MOREIRA e SIQUEIRA, 2002; PFLEGER et al., 1994; SOUZA et al., 2010). Caproni et al. (2007) destacam que o pH, Al, P e a textura argilosa podem limitar o desenvolvimento e a ocorrência de espécies de FMAs. Silva et al. (2007) verificaram que, enquanto espécies de Acaulospora podem tolerar ampla faixa de $\mathrm{pH}$, Entrophospora infrequens têm preferência por solos ácidos, e Glomus mosseae por solos neutros a levemente alcalinos. Guadarrama e Alvarez Sânchez (1999) ressaltam que a fenologia das plantas pode atuar como um possível regulador da esporulação, tendo observado, 
que o número de esporos aumenta quando as raízes diminuem sua taxa de crescimento.

Especula-se que fatores do solo que influenciam os fungos micorrízicos arbusculares também interferem na produção de glomalina (glicoproteína produzida por estes fungos), uma vez que a presença e o tipo de vegetação afetam a produção da mesma (BIRD et al., 2002). A glomalina é considerada uma proteína estável e abundante no solo (RILLIG et al., 2003), encontrando-se estreitamente correlacionada com a estabilidade de agregados e com o carbono e o nitrogênio do solo (NICHOLS e WRIGHT, 2005). Purin (2005) observou correlação altamente significativa entre a glomalina e o carbono orgânico total em área de campo nativo, durante a época de inverno $(\mathrm{r}=$ $0,892 ; \mathrm{p}=0,017)$, em solos tropicais, da mesma forma que Bedini et al. (2007), em três tipos de uso (monocultivo de milho, floresta não manejada e campo nativo) localizados em condições de clima temperados. Alguns estudos também demonstram relação negativa e/ou ausência de relação entre esta proteína e os teores de $\mathrm{Ca}, \mathrm{Mg}, \mathrm{P}, \mathrm{K}$ e pH do solo (LOVELOCK et al. 2004; MERGULHÃO et al., 2006; RILLIG et al., 2003).

Em função do exposto, esse trabalho teve como objetivo avaliar a influência da revegetação de uma área degradada pela extração de argila, com Eucalyptus camaldulensis e Acacia mangium, em plantios puros ou consorciados, na composição e na diversidade de fungos micorrízicos arbusculares (FMAs), bem como na produção da proteína do solo relacionada à glomalina (PSRG).

\section{MATERIAL E MÉTODOS}

\section{Descrição da área de estudo}

O trabalho foi realizado em uma cava de extração de argila pertencente à Cerâmica Stilbe Ltda., localizada no distrito de Poço Gordo ( $21^{\circ} 50^{\prime}$ 28,5" S; 41 14'31,4” W), município de Campos dos Goytacazes, RJ. O clima da região norte fluminense é classificado de acordo com Köppen do tipo Aw, tropical quente e úmido, com período seco no inverno e chuvoso no verão, e com precipitação anual em torno de $1020 \mathrm{~mm}$. As médias de temperatura e precipitação da área em estudo, registradas no período de maio de 2006 a junho de 2007 , foram de $24,1^{\circ} \mathrm{C}$ e $86,6 \mathrm{~mm}$, respectivamente.

$\mathrm{O}$ solo original da área da cava em estudo é um Cambissolo Háplico Sódico Gleico, com profundidade de aproximadamente $3 \mathrm{~m}$, onde a camada superficial com maior conteúdo de matéria orgânica foi retirada e devolvida ao fundo da cava após a extração da argila. A cava foi nivelada mecanicamente e mantida sob pousio durante dois anos, surgindo como vegetação espontânea a braquiária [Brachiaria mutica (Forsk.) Stapf.] (SCHIAVO, 2005).

Após o período de pousio, realizou-se o preparo da área com uma aração e duas gradagens. A cava foi revegetada, em agosto de 2002, com Acacia mangium e Eucalyptus camaldulensis em plantios puros e consorciados (SCHIAVO, 2005) utilizandose um espaçamento de dois metros entre plantas e três metros entre linhas $(2 \times 3)$. Realizou-se uma adubação nas covas com fosfato de rocha Araxá, sendo a dose aplicada equivalente a $100 \mathrm{mg} \mathrm{kg}^{-1} \mathrm{de}$ solo.

O delineamento experimental utilizado foi o de blocos ao acaso com quatro tratamentos e três repetições, sendo os tratamentos: plantios puros de Eucalyptus camaldulensis e Acacia mangium; consórcio de Eucalyptus camaldulensis + Acacia mangium; e área degradada com vegetação espontânea (ADVE). Entre os plantios foram alocadas duas linhas de plantas de Eucalyptus camaldulensis que constituíram a bordadura. A parcela experimental foi constituída por 16 plantas.

$\mathrm{Na}$ fase de produção de mudas, as espécies foram inoculadas com FMAs (Glomus macrocarpum, Glomus etunicatum e Entrophospora colombiana) isolados de uma área de extração de argila, pertencente à Cerâmica Caco Manga Ltda., localizada no distrito de Ururaí, no município de Campos dos Goytacazes-RJ. O isolado, pertencente ao banco de inóculo do laboratório de solos da UENF (Universidade Estadual do Norte Fluminense), foi multiplicado em plantas de Brachiaria brizantha em mistura de solo + areia, na proporção de 1:2 (v:v). Além dos FMAs, a Acacia mangium foi inoculada (na semente) com estirpe específica de rizóbio (BR 3609 e BR 6009). As estirpes foram provenientes da Embrapa Agrobiologia, Seropédica-RJ.

\section{Amostragem}

A amostragem foi realizada (setembro/2006) na profundidade de $0-5 \mathrm{~cm}$, na entrelinha dos plantios. Em cada parcela foram coletadas 10 amostras simples de terra, que, misturadas, resultaram em uma amostra composta por parcela. No ato da amostragem as parcelas com os plantios das espécies arbóreas apresentavam-se com quatro anos de idade, enquanto a ADVE com seis anos. 
As amostras de solo foram previamente secas à sombra, acondicionadas em sacolas plásticas e armazenadas a $10^{\circ} \mathrm{C}$, para isolamento de esporos de FMA, quantificação da proteína do solo relacionada à glomalina e encaminhamento para análise das características químicas (Tabela 1).

\section{Extração dos esporos e identificação das espécies de FMAs}

De cada amostra de solo foram retirados $50 \mathrm{~cm}^{3}$ de terra para as extrações dos esporos dos FMAs, seguindo a técnica de peneiramento úmido (GERDERMANN e NICOLSON, 1963). Após a contagem, os esporos foram transferidos para uma placa de Petri e uma quarta parte do total dos esporos foi separada aleatoriamente. Estes foram separados em dois grupos, sendo um grupo disposto na lâmina com álcool polivinil em lactoglicerol (PVLG) sob uma lamínula, e o outro grupo, disposto nesta mesma lâmina, com reagente de Melzer, sob outra lamínula.

Os esporos foram observados em microscópio ótico com iluminação de campo claro e objetiva de imersão. A identificação das espécies de FMAs foi feita de acordo com Schenck e Perez (1988) e utilizando a descrição morfológica disponível na internet na página da International Culture Collection of Arbuscular Mycorrhizal Fungi (http://invam.caf.wwu.edu/). Os caracteres taxonômicos observados foram: número e tipo de camadas das paredes dos esporos e sua reação ao reagente de Melzer; características das paredes internas, quando presentes; morfologia da hifa de sustentação do esporo; e variação da cor e tamanho dos esporos.

Foram estimados a riqueza média de espécies de FMAs e os índices de riqueza de espécies Shannon-Wiener, de dominância de Simpson e de equabilidade de Pielou em cada amostra de solo. Além disso, foram avaliadas a abundância de esporos (AE), a frequência de ocorrência (Fi), a abundância relativa (ARi), a abundância de esporos de cada espécie (Ai) e o índice de abundância e frequência (IAF) para cada espécie, em cada tratamento. As espécies foram classificadas em quatro categorias, as quais representam as suas contribuições na comunidade total de esporos: nenhuma importância (IAF $=0$ ); pouca importância $(0<\mathrm{IAF} \leq 10)$; moderada importância $(10<\mathrm{IAF} \leq 30)$; grande importância (IAF>30) (KOSKE e GEMA, 1997) (Tabela 2).

\section{Proteína do solo relacionada à glomalina - extração e quantificação}

A glomalina no solo foi quantificada como proteína do solo relacionada à glomalina (PSRG). Duas frações de PSRG (glomalina facilmente extraível - GFE; glomalina total - GT) foram distinguidas em função das condições de extração e do método de quantificação (RILLIG, 2004; WRIGHT e UPDAHYAYA, 1998). A proteína do solo relacionada à glomalina - facilmente extraível (PSRG-FE) foi obtida a partir da extração em autoclave, utilizando-se $1 \mathrm{~g}$ de solo e $8 \mathrm{ml}$ de solução de citrato de sódio $20 \mathrm{mM}(\mathrm{pH} 7,4)$, a uma temperatura de $121^{\circ} \mathrm{C}$ por $30 \mathrm{~min}$. A quantidade de proteína do solo relacionada à glomalina - total (PSRG - T) foi obtida utilizando-se $1 \mathrm{~g}$ de solo e 8 $\mathrm{ml}$ de citrato de sódio $50 \mathrm{mM}$, com $\mathrm{pH} 8,0$ a $121^{\circ} \mathrm{C}$, por $60 \mathrm{~min}$. Para extração desta fração, foram necessários mais de um ciclo de autoclavagem (3 a 10 ciclos dependendo da amostra), até que a

TABELA 1: Características químicas da camada 0-5 $\mathrm{cm}$ do solo da área degradada pela extração de argila, com vegetação espontânea (ADVE) e revegetada com Acacia mangium e Eucalyptus camaldulensis, em plantios puros e consorciados. COT - carbono orgânico total.

TABLE 1: Chemical characteristics of the $0-5 \mathrm{~cm}$ soil layer of the degraded area by clay mining, covered with spontaneous vegetation (ADVE) or revegetated with Acacia mangium and Eucalyptus camaldulensis in pure or mixed plantings. COT - total organic carbon.

\begin{tabular}{lccccccccccc}
\hline \multicolumn{1}{c}{ Tratamentos } & $\mathrm{pH}$ & $\mathrm{COT}$ & $\mathrm{N}$ & $\mathrm{P}$ & $\mathrm{Ca}$ & $\mathrm{Mg}$ & $\mathrm{K}$ & $\mathrm{Na}$ & $\mathrm{Al}$ & $\mathrm{H}+\mathrm{Al}$ \\
& & $\ldots . . \mathrm{g} \mathrm{kg}^{-1} \ldots \ldots$ & $\mathrm{mg} \mathrm{dm}^{-3}$ & \multicolumn{7}{c}{$\ldots \ldots \ldots \ldots \ldots \ldots \ldots . . . \ldots \mathrm{cmol}_{\mathrm{c}} \mathrm{dm}^{-3} \ldots \ldots \ldots \ldots \ldots \ldots \ldots$} \\
\hline Eucalipto & 5,64 & 27,60 & 1,50 & 65,77 & 6,20 & 4,12 & 1,22 & 1,52 & 0,10 & 2,86 \\
Acácia & 4,88 & 25,67 & 1,90 & 26,63 & 5,51 & 5,02 & 0,77 & 2,78 & 0,00 & 4,62 \\
Consórcio & 5,58 & 19,61 & 1,40 & 20,70 & 7,86 & 4,83 & 1,44 & 0,63 & 0,00 & 3,14 \\
ADVE & 6,82 & 11,92 & 0,50 & 14,66 & 3,85 & 2,48 & 0,39 & 2,59 & 0,10 & 0,95 \\
\hline
\end{tabular}


TABELA 2: Procedimento usado para descrever as comunidades de FMAs.

TABLE 2: Procedure used to describe the AMF communities.

\begin{tabular}{|c|c|}
\hline Denominação & Fórmula \\
\hline Riqueza média de espécies (RME) & $\mathrm{RME}=\mathrm{n}^{\mathrm{o}}$ médio de espécies FMAs identificadas na amostra de solo \\
\hline $\begin{array}{l}\text { Índice de diversidade Shannon-Wiener (ISW) } \\
\text { (HENDRIX et al., 1995) }\end{array}$ & $\mathrm{ISW}=-\sum(\mathrm{Xi} / \mathrm{Xo}) \times \log (\mathrm{Xi} / \mathrm{Xo})$ \\
\hline $\begin{array}{l}\text { Índice de dominância de Simpson (IDS) } \\
\text { (HENDRIX et al., 1995) }\end{array}$ & $\mathrm{IDS}=(\mathrm{Xi} / \mathrm{Xo})^{2}$ \\
\hline $\begin{array}{l}\text { Índice de Equabilidade de Pielou (IEP) } \\
\text { (PIELOU, 1966) }\end{array}$ & $\mathrm{IEP}=\mathrm{H}^{\prime} / \mathrm{H}^{\prime} \max$ \\
\hline Abundância de esporos (AE) & $\mathrm{AE}=\mathrm{n}^{\circ}$ de esporos em $50 \mathrm{~cm}^{3}$ de solo \\
\hline $\begin{array}{l}\text { Frequência de ocorrência (Fi) } \\
\text { (BROWER et al. 1990) }\end{array}$ & $\mathrm{Fi}=\mathrm{ji} / \mathrm{K}$ \\
\hline $\begin{array}{l}\text { Abundância relativa (ARi) } \\
\text { (BROWER et al. 1990) }\end{array}$ & $\mathrm{ARi}=\mathrm{ni} / \sum \mathrm{n}$ \\
\hline Abundância de esporos de cada espécie (Ai) & $\mathrm{Ai}=\mathrm{n}^{\circ}$ de esporos de cada espécie em $50 \mathrm{~cm}^{3}$ de solo \\
\hline $\begin{array}{l}\text { Índice de abundância e frequência (IAFi) } \\
\text { (KOSKE e GEMMA, 1997) }\end{array}$ & $\mathrm{IAFi}=(\mathrm{FRi}+\mathrm{ARi} \times 100)$ \\
\hline $\begin{array}{l}\text { Frequência relativa de cada espécie (FRi) } \\
\text { (BROWER et al. 1990) }\end{array}$ & $F R i=f i / \sum f$ \\
\hline
\end{tabular}

Em que: ni = número total de esporos da espécie $\mathrm{i}$, em $50 \mathrm{~cm}^{-3}$ de solo; $\sum \mathrm{n}=$ soma do número dos esporos de todas as espécies em $50 \mathrm{~cm}^{-3}$ de solo; $\mathrm{ji}=$ número de amostras nas quais a espécie i ocorreu; $\mathrm{k}=$ número total de amostras de solo; $\mathrm{fi}=$ frequência de ocorrência de uma dada espécie $\mathrm{i} ; \sum \mathrm{f}=$ soma das frequências de todas as espécies; $\mathrm{Xi}=$ densidade de esporos de cada espécie em $50 \mathrm{~cm}^{-3}$ de solo; Xo = densidade total de esporos de todas as espécies; H'max = máximo $\mathrm{H}^{\prime}$ calculado pela seguinte fórmula: $\mathrm{H}^{\prime}=\log (\mathrm{S})$, onde $\mathrm{S}$ é o número total de espécies identificadas por amostra.

amostra atingisse a cor amarelo-clara. Em ambas as frações, posteriormente à autoclavagem, foi realizada centrifugação a $5000 \mathrm{X}$ g por $20 \mathrm{~min}$, onde o sobrenadante foi removido para posterior quantificação da proteína. A quantificação da glomalina foi realizada pelo método Bradford (1976) modificada por Wright et al. (1996), disponível no site www.usda.gov, usando como padrão soro-albumina bovina. As concentrações da glomalina, para ambas as frações, foram corrigidas para $\mathrm{mg} \mathrm{g}^{-1}$ de solo, considerando-se o volume total de sobrenadante e a massa seca do solo.

\section{Análise dos dados}

Os dados foram avaliados quanto à homocedastia, pelo teste de Cochran (SNEDECOR e COCHRAN, 1989), e distribuição normal dos resíduos, pelo teste de Lilliefors (CAMPOS, 1979). Posteriormente, foram submetidos à análise de variância e ao teste de médias Scott Knott ( $\alpha=$ $0,05)$. As relações entre os atributos edáficos foram determinadas por análise de correlação de Pearson.

\section{RESULTADOS E DISCUSSÃO}

\section{Diversidade de espécies e abundância de esporos de FMAs}

Na tabela 3 pode ser observada a diversidade de fungos micorrízicos arbusculares nas áreas estudadas, onde foi encontrado um total de 12 espécies pertencentes a cinco gêneros. Algumas das espécies observadas nesse estudo já foram encontradas em áreas degradadas por processos de mineração e revegetadas (BATISTA et al., 2009; CAPRONI et al., 2003, 2005, 2007; MELLONI et al., 2003).

O número de espécies identificadas neste estudo foi superior ao encontrado por Melloni et al. (2003) (seis espécies) em áreas de mineração de bauxita com diferentes tipos de vegetação, e por Mehrotra (1998) em solos de mineração de carvão na Índia, revegetados há sete anos com diferentes espécies arbóreas (seis espécies). Todavia, foi inferior ao encontrado por Batista et al. (2009) em cava de extração de argila revegetada com diferentes espécies de eucalipto e sabiá (18 espécies). 
TABELA 3: Espécies de FMAs em amostras de solo coletas de área degradada pela extração de argila, com vegetação espontânea (ADVE) e revegetada com Acacia mangium e Eucalyptus camaldulensis, em plantios puros e consorciados.

TABLE 3: AMF species in the soil samples collected from degraded area by clay mining, covered with spontaneous vegetation (ADVE) or revegetated with Acacia mangium and Eucalyptus camaldulensis in pure or mixed plantings.

\begin{tabular}{|c|c|}
\hline Sistemas & Espécies de FMAs \\
\hline Eucalipto & $\begin{array}{l}\text { Glomus tortuosum; Glomus macrocarpum; Glomus sp 1; Glomus sp 2; Gigaspora sp. e } \\
\text { Archaeospora leptoticha }\end{array}$ \\
\hline Acácia & $\begin{array}{l}\text { Glomus tortuosum; Glomus clarum; Glomus sp 1; Glomus sp 2; Glomus macrocarpum; } \\
\text { Acaulospora mellea; Acaulospora foveata; Archaeospora leptoticha }\end{array}$ \\
\hline Consórcio & $\begin{array}{l}\text { Glomus tortuosum; Glomus clarum; Glomus macrocarpum; Acaulospora laevis; } \\
\text { Acaulospora scrobiculata; Acaulospora mellea; Archaeospora leptoticha e } \\
\text { Scutellospora sp } 1\end{array}$ \\
\hline ADVE & Glomus macrocarpum e Acaulospora scrobiculata \\
\hline
\end{tabular}

Caproni (2001) relatou que as espécies de fungos em áreas tropicais são mais diversas que em áreas de clima temperado, sendo que este número de espécies pode estar associado à diversidade da vegetação no local, a idade do povoamento, as características do solo e ao tempo de amostragem (CAPRONI et al., 2005).

O maior número de espécies encontradas neste estudo, pertence ao gênero Glomus (cinco espécies), seguido pelo gênero Acaulospora (quatro espécies), e Scutellospora, Archaeospora e Gigaspora sp. (uma espécie cada) (Tabela 3). Esta sequência é semelhante à encontrada por Caproni et al. (2005) em plantios de Acacia mangium com um e cinco anos de idade, em estéril de mineração de bauxita. As espécies Glomus tortuosum e Archaeospora leptoticha foram encontradas em todos os sistemas de plantio, exceto na área ADVE (Tabela 3). Batista et al. (2009) também observaram este padrão para a espécie Glomus tortuosum em cava de extração de argila degradada e revegetada com sabiá e diferentes espécies de eucalipto.

No que se refere à riqueza média, observouse que os plantios, quando comparados à área com vegetação espontânea, apresentaram maior número de espécies. Além disso, verificou-se um maior índice de diversidade de Shannon-Wiener (ISW) e índice de equabilidade de Pielou (IEP) nos plantios (Tabela 4). Por outro lado, a dominância de espécies representada pelo índice de Simpson (IDS) foi mais baixa. Assim, quando se faz uma comparação do ISW com o IDS, verifica-se que onde a diversidade das espécies foi mais alta, a dominância foi mais baixa, tal como observado por Caproni et al. (2003) em áreas revegetadas após mineração de bauxita, em Porto Trombetas-PA. Estes autores observaram que os valores de ISW foram significativamente maiores na área revegetada em relação à não revegetada. Carrenho et al. (2001) discutem que florestas com altura e complexidade estrutural mais elevada criam mais micro-habitats e microclimas, o que favorece a diversidade dos microrganismos do solo.

Para os índices de ISW e IDS, observou-se que o eucalipto em monocultivo apresentou menor diversidade e maior dominância, em relação ao consórcio com a leguminosa (Tabela 4). Na ADVE, embora tenha apresentado uma elevada abundância de esporos de FMAs, sua diversidade (ISW) foi baixa (Tabela 4). Odum (1989) destaca que em ambientes homogêneos a abundância tende a ser alta e a diversidade tende a diminuir. Esse aspecto tem sido considerado de grande importância para a melhora da dinâmica da matéria orgânica do solo, o que favorece a ciclagem de nutrientes e o crescimento vegetal (LAVELLE e SPAIN, 2001).

A abundância de esporos (AE) de FMAs nos diferentes plantios e na área degradada com vegetação espontânea (ADVE) mostrou uma variação de 165 a 1126 esporos por $50 \mathrm{~cm}^{3}$ de solo, sendo a menor média encontrada no plantio de eucalipto e a maior média na ADVE. As áreas de plantio não apresentaram diferença significativa entre si, contudo, foram estatisticamente diferentes da áreaADVE, tendo, essa última, apresentado maior número de esporos em relação aos plantios (Tabela 4). Estes resultados não são corroborados pelos de Batista et al. (2009) em experimento de Mimosa caesalpiniifolia (sabiá) e diferentes espécies de 
TABELA 4: Riqueza média de espécies (RME), índice de diversidade de Shannon-Wiener (ISW), índice de equabilidade de Pielou (IEP), índice de dominância de Simpson (IDS) e abundância de esporos (AE) em $50 \mathrm{~cm}^{3}$ de solo, das amostras de solo coletas de área degradada pela extração de argila, com vegetação espontânea (ADVE) e revegetada com Acacia mangium e Eucalyptus camaldulensis, em plantios puros e consorciados.

TABLE 4: Average species richness (RME), Shannon-Wiener Diversity Index (ISW), Pielou's evenness index (CI) Simpson dominance index (SDI) and abundance of spores (AE) in $50 \mathrm{~cm}^{3}$ of soil, of the soil samples collected from degraded area by clay mining, covered with spontaneous vegetation (ADVE) or revegetated with Acacia mangium and Eucalyptus camaldulensis in pure or mixed plantings.

\begin{tabular}{lccccl}
\hline Sistemas & RME & ISW & IEP & IDS & AE \\
\hline Eucalipto & $3 \mathrm{~b}$ & $0,24 \mathrm{~b}$ & $0,63 \mathrm{a}$ & $0,66 \mathrm{~b}$ & $165 \mathrm{~b}$ \\
Acácia & $6 \mathrm{a}$ & $0,51 \mathrm{a}$ & $0,72 \mathrm{a}$ & $0,41 \mathrm{c}$ & $386 \mathrm{~b}$ \\
Consórcio & $4 \mathrm{~b}$ & $0,44 \mathrm{a}$ & $0,78 \mathrm{a}$ & $0,36 \mathrm{c}$ & $244 \mathrm{~b}$ \\
ADVE & $2 \mathrm{c}$ & $0,09 \mathrm{~b}$ & $0,18 \mathrm{~b}$ & $0,89 \mathrm{a}$ & $1226 \mathrm{a}$ \\
\hline
\end{tabular}

Em que: Médias seguidas de mesma letra na coluna não diferem pelo teste Scott Knott a $5 \%$.

eucalipto em plantios puros e consorciados, em cava de extração de argila, na região norte fluminense, Rio de Janeiro.

A ocorrência de maior número de esporos encontrada na ADVE pode estar relacionada à presença de gramíneas, bem como à condição mais estressante deste ambiente, levando os FMAs a produzirem um elevado número de propágulos com o intuito de sobrevivência, embora se verifique que a maioria dos estresses reduza a esporulação (SYLVIA e JARSTFER, 1992). Silva et al. (2006) observaram um menor número de esporos em solos com vegetação nativa em relação a agrossistemas com influência antrópica. Esses autores atribuem esse padrão à maior estabilidade do ecossistema, com horizontes superficiais mais protegidos contra perturbações bruscas, bem como, a menor competição por nichos, garantindo a sobrevivência das espécies com baixa esporulação (CAPRONI et al., 2003).

\section{Frequência de ocorrência e abundância relativa}

As espécies de FMAs encontradas nas amostras de terra recolhidas na área da cava em ordem decrescente de ocorrência foram: Glomus tortuosum = Glomus macrocarpum $>$ Acaulospora scrobiculata $>$ Archaeospora leptoticha $>$ Glomus clarum $=$ Acaulospora mellea $>$ Glomus sp. $2>$ Glomus sp. $1>$ Acaulospora foveata $=$ Acaulospora laevis $=$ Gigaspora sp. $=$ Scutellospora sp. $($ Tabela 5).

Embora Glomus tortuosum tenha apresentado frequência de ocorrência (58 \%) equivalente à espécie Glomus macrocarpum, foi esta última que apresentou maior abundância relativa (Tabela 5). Caproni et al. (2003) também relataram em seu trabalho altas concentrações de propágulos de Glomus macrocarpum, bem como maior número de esporos, independentemente das condições do substrato. A alta abundância relativa do gênero Glomus, especialmente da espécie citada acima, indicou sua maior capacidade de esporulação ou alta adaptabilidade à região e às situações iniciais de sucessão, como também destacado por Caproni et al. (2003).

As espécies Glomus macrocarpum e Archaeospora leptoticha, parecem estar amplamente distribuídas no Brasil, sendo relatadas em vários trabalhos sobre a ocorrência de FMAs em plantas cultivadas (BATISTA et al., 2009; CAPRONI et al., 2003, 2005, 2007; SANTOS, 2010; SILVA et al., 2006; SILVA et al., 2007). A espécie Glomus macrocarpum tem sido encontrada em áreas com $\mathrm{pH}$ variando de 3,4 a 3,6 revegetadas após mineração de bauxita (CAPRONI et al., 2003) e naquelas revegetadas após mineração de carvão, sendo o $\mathrm{pH}$ encontrados nessas áreas entre 3,2 e 7,1 (KIERMAN et al., 1983), o que demonstra sua ampla faixa de adaptação. Neste estudo, Glomus macrocarpum ocorreu em solos com $\mathrm{pH}$ variando de 4,88 a 6,82. Enquanto a espécie Acaulospora foveata ocorreu apenas na área com plantio de acácia, cujo solo apresentou $\mathrm{pH}$ de 4,88 (Tabelas 1 e 3 ).

Dentre as espécies de FMAs (Glomus macrocarpum, Glomus etunicatum e Entrophospora colombiana) inoculadas nas espécies arbóreas, apenas Glomus macrocarpum foi encontrada, 
TABELA 5: Frequência de ocorrência (Fi) e abundância relativa (AR) de esporos por espécie de FMA encontrada em amostras de solo coletadas em de área degradada pela extração de argila, com vegetação espontânea (ADVE) e revegetada com Acacia mangium e Eucalyptus camaldulensis, em plantios puros e consorciados.

TABLE 5: Frequency of occurrence (Fi) and relative abundance (AR) of spores by each AMF species found in soil samples collected from degraded area by the clay mining, covered with spontaneous vegetation (ADVE) or revegetated with Acacia mangium and Eucalyptus camaldulensis in pure or mixed plantings.

\begin{tabular}{lcc}
\hline \multicolumn{1}{c}{ Espécies de FMAs } & Fi (\%) & AR(\%) \\
\hline Glomus macrocarpum & Família Glomaceae & 67 \\
Glomus tortuosum & 58 & 11 \\
Glomus clarum & 58 & 4 \\
Glomus sp. 1 & 33 & 1 \\
Glomus sp. 2 & 17 & 2 \\
& 25 & \\
Archaeospora leptoticha & Família Archaeosporaceae & 5 \\
Acaulospora mellea & 42 & 2 \\
Acaulospora scrobiculata & Família Acaulosporaceae & 4 \\
Acaulospora foveata & 33 & 0,1 \\
Acaulospora laevis & 50 & 2 \\
Gigaspora sp. & 8 & 0,1 \\
Scutellospora sp. & 8 & 0,2 \\
\hline
\end{tabular}

inclusive na ADVE (Tabela 4). Levando-se em consideração que essas três espécies são nativas da área de cava de extração de argila e que só Glomus macrocarpum foi encontrada, é possível que os plantios estabelecidos na área de estudo não estejam estimulando a esporulação das demais espécies, ou esse padrão pode ser decorrente do momento da amostragem (solo seco), ou da capacidade competitiva destas espécies. É importante ressaltar também, que dependendo do grau de distúrbio, determinadas espécies podem ficar durante muito tempo sem esporular ou até mesmo desaparecer do local (FOCCHI et al., 2004).

\section{Índice de abundância e frequência das espécies}

Os FMAs Glomus macrocarpum, Glomus tortuosum, Glomus clarum, Archaeospora leptoticha, Acaulospora mellea e Acaulospora scrobiculata apresentaram alto valor de importância em, pelo menos, um dos plantios. Glomus tortuosum apresentou alto índice de abundância e frequência
(IAF) em todos os plantios, enquanto Glomus clarum se destacou apenas no consórcio de acácia com eucalipto (Tabela 6). Caproni et al (2005) encontraram alto IAF para a espécie Glomus clarum em estéril de mineração de bauxita sob plantio de Acacia mangium com 1 ano de idade, o que demonstrou um nítido efeito da inoculação desta espécie nas mudas. Por outro lado, nesse mesmo estudo, em plantio da mesma leguminosa aos 5 anos de idade, as espécies que apresentaram um elevado valor de importância foram Acaulospora mellea e Glomus macrocarpum, enquanto Glomus clarum apresentou IAF baixo. Estes dados estão de acordo com os resultados observados neste trabalho, uma vez que, tanto Acaulospora mellea quanto Glomus macrocarpum apresentaram alto IAF no plantio de acácia aos quatro anos de idade (Tabela 6).

A espécie Gigaspora sp apresentou valor de IAF classificado como de moderada importância ( $\mathrm{IAF}=12)$ no plantio de eucalipto, não sendo encontrada $(\mathrm{IAF}=0)$ nos demais plantios 
(Tabela 6). Este padrão pode estar indicando uma baixa competitividade desta espécie fúngica em campo, tal como observado para a espécie Gigaspora margarita em estéril de mineração de bauxita revegetado com Acacia mangium após 1 e 5 anos de idade (CAPRONI et al., 2005). Por este índice sugere-se que as espécies Glomus macrocarpum, Archaeospora leptoticha, Glomus clarum, Acaulospora mellea e em especial Glomus tortuosum, se destacaram como espécies a serem consideradas em programas de revegetação, principalmente em cavas de extração de argila, apresentando, em pelo menos um dos plantios, alto valor de IAF (IAF>30). Assim, resta apenas observar sua eficiência simbiótica, visto que, estas espécies se adaptaram bem a tais condições ambientais adversas. De acordo com Marinho et al. (2004) e Mergulhão (2006), FMAs com baixo IAF, geralmente têm maior dificuldade de adaptação em áreas de mineração, sugerindo que o ambiente estudado possa apresentar fatores limitantes à expressão da capacidade gênica de alguns fungos em se estabelecer.

\section{Proteína do solo relacionada à glomalina}

As médias da proteína do solo relacionada à glomalina - facilmente extraível (PSRG-FE) variaram entre 0,28 e $1,27 \mathrm{mg} \mathrm{g}^{-1}$ de solo na ADVE e plantio com leguminosa, respectivamente. Entre os diferentes plantios a variação foi de 1,03 a $1,27 \mathrm{mg} \mathrm{g}^{-1}$ de solo (Tabela 7). Esses valores estão próximos aos encontrados por Mergulhão (2006) em área de caatinga nativa. Contudo, são aproximadamente o dobro dos valores observados em sistemas agrícolas e florestas nativas de Ohio, USA (RILLIG et al., 2003). De acordo com Purin (2005), vários fatores são determinantes para a produção e a decomposição da PSRG-FE de maneira que a variação de quantidades desta proteína de uma região para outra é de difícil explicação, e consiste em um aspecto que necessita de futuros esclarecimentos.

Maiores concentrações de PSRG-FE e PSRG-T foram registradas nos plantios, quando comparadas à ADVE. Somente na fração GT observou-se diferença significativa entre os plantios. As maiores concentrações desta fração

TABELA 6: Índice de abundância e frequência (IAF) das espécies de FMAs em cada plantio e na área degradada com vegetação espontânea (ADVE).

TABLE 6: Frequency and abundance Indexes (IAF) of AMF species in each plantation and in degraded area with spontaneous vegetation (ADVE).

\begin{tabular}{lcccc}
\hline \multicolumn{1}{c}{ Espécies de FMAs } & Eucalipto & Acácia & Consórcio & ADVE \\
\hline Glomus macrocarpum & Família Glomaceae & & & \\
Glomus tortuosum & 19 & 58 & 30 & 128 \\
Glomus clarum & 74 & 51 & 42 & - \\
Glomus sp. 1 & - & 12 & 69 & - \\
Glomus sp. 2 & 19 & 14 & - & - \\
& 27 & 26 & - & - \\
Archaeospora leptoticha & Família Archaeosporaceae & & & - \\
& 49 & 33 & 15 & - \\
Acaulospora mellea & Família Acaulosporaceae & & & 39 \\
Acaulospora scrobiculata & - & 45 & 14 & - \\
Acaulospora foveata & - & 15 & 24 & - \\
Acaulospora laevis & - & 12 & - & - \\
Gigaspora sp. & - & - & 27 & - \\
Scutellospora sp. 1 & Família Gigasporaceae & & - & \\
\hline
\end{tabular}

Em que: (-) não detectado (IAF=0) 
foram encontradas nos plantios puros de acácia e de eucalipto em relação ao consórcio (Tabela 7).

De acordo com Mergulhão(2006), o impacto antrópico representado pela exploração mineral pode prejudicar a produção de micélio externo, responsável pela síntese de glomalina. Assim, a presença de espécies arbóreas tende a estimular a ocorrência de FMAs e, consequentemente, aumentar a deposição desta proteína ao solo. Além disso, tem sido verificada diferença entre as espécies de FMAs no que diz respeito à produção desta proteína (WRIGHT e UPADHYAYA, 1996). Desta forma, a diversidade de FMAs, bem como a presença de vegetação estimulando a ocorrência de FMAs, pode ajudar a explicar a variação de PSRG-FE e PSRG-T entre os plantios e a ADVE. Nesse estudo não foi observada correlação entre a produção de glomalina e o número de espécies de FMAs. Ao contrário da abundância de esporos onde a correlação foi linear negativa para a fração PSRG-FE (Tabela 8).

Outro fator importante que poderia explicar a maior quantidade de GFE nos plantios, em relação à ADVE, é a decomposição das hifas. Lutgen et al. (2003) relatam que quanto maior a decomposição, mais GFE é liberada para o solo. A avaliação da fauna edáfica realizada nesta mesma área de estudo, mostrou nos solos sob os plantios, a presença de invertebrados (colêmbolos) que se alimentam de microrganismos, os quais não foram encontrados na ADVE (SILVA, 2009). Os colêmbolos se alimentam principalmente de hifas de fungos e, de acordo com Rusek (1998), ao se alimentarem desta estrutura, beneficiam o crescimento dos fungos, principalmente, pela dispersão de propágulos e pela remoção de hifas velhas induzindo o crescimento compensatório.

Existem relatos de que, em áreas preservadas, as quantidades de glomalina total extraídas são superiores a $60 \mathrm{mg} \mathrm{g}^{-1}$ de solo (RILLIG et al., 2001), porém, nesse estudo os valores encontrados foram menores (Tabela 7). Avaliando a concentração de PSRG em áreas de

TABELA 7: Proteína do solo relacionada à glomalina - total (PSRG -T) e facilmente extraível (PSRG-FE) (mg g-1 solo) em amostras de solo de área degradada pela extração de argila, com vegetação espontânea (ADVE) e revegetada com Acacia mangium e Eucalyptus camaldulensis, em plantios puros e consorciados.

TABLE 7: Glomalin-related soil protein - total (PSRG-T) and easily extractable (PSRG-FE) in soil samples from area degraded by clay mining, site with weeds (ADVE) or revegetated with Acacia mangium and Eucalyptus camaldulensis in pure or mixed plantings.

\begin{tabular}{lcc}
\hline Sistemas & PSRG-T & PSRG-FE \\
\hline Eucalipto & $5,36 \mathrm{a}$ & $1,03 \mathrm{a}$ \\
Acácia & $5,57 \mathrm{a}$ & $1,27 \mathrm{a}$ \\
Consórcio & $3,16 \mathrm{~b}$ & $1,05 \mathrm{a}$ \\
ADVE & $0,55 \mathrm{c}$ & $0,28 \mathrm{~b}$ \\
\hline
\end{tabular}

Em que: Médias seguidas de mesma letra na coluna não diferem pelo teste Scott Knott a $5 \%$.

TABELA 8: Coeficientes de correlação de Pearson ( $\mathrm{r}$ ) entre variáveis químicas e biológicas $(\mathrm{P}<0,05)$. PSRG-T = proteína do solo relacionada à glomalina-total; PSRG-FE = proteína do solo relacionada à glomalina-facilmente extraível; $\mathrm{AE}=$ Abundância de Esporos; $\mathrm{NE}=$ Número de Espécies; $\mathrm{ns}=$ não significativo; $\mathrm{AF}=$ ácido fúlvico; $\mathrm{AH}=$ ácido húmico; $\mathrm{HU}=$ humina; COT= carbono orgânico total.

TABLE 8: Pearson correlation coefficients ( $r)$ between chemical and biological variables $(\mathrm{P}<0.05)$. PSRG-T = total glomalin-related soil protein; PSRG-FE = Easily extractable Glomalin related soil protein; $\mathrm{AE}=$ spores abundance; $\mathrm{NE}=$ Number of Species; $\mathrm{ns}=$ not significant; $\mathrm{AF}=$ fulvic acid; $\mathrm{AH}=$ humic acid; $\mathrm{HUM}=$ humin; $\mathrm{COT}=$ total organic carbon.

\begin{tabular}{cccccccccccccccc}
\hline & PSRG-FE & $\mathrm{pH}$ & $\mathrm{COT}$ & $\mathrm{AF}$ & $\mathrm{AH}$ & $\mathrm{HU}$ & $\mathrm{N}$ & $\mathrm{P}$ & $\mathrm{Ca}$ & $\mathrm{Mg}$ & $\mathrm{K}$ & $\mathrm{Na}$ & $\mathrm{H}+\mathrm{Al}$ & $\mathrm{AE}$ & $\mathrm{NE}$ \\
\hline PSRG-T & 0,91 & $\mathrm{~ns}$ & 0,99 & $\mathrm{~ns}$ & 0,99 & 0,98 & 0,94 & $\mathrm{~ns}$ & $\mathrm{~ns}$ & $\mathrm{~ns}$ & $\mathrm{~ns}$ & $\mathrm{~ns}$ & $\mathrm{~ns}$ & $\mathrm{~ns}$ & $\mathrm{~ns}$ \\
PSRG-FE & - & $-0,98$ & 0,87 & 0,95 & 0,94 & $\mathrm{~ns}$ & 0,99 & $\mathrm{~ns}$ & $\mathrm{~ns}$ & 0,97 & $\mathrm{~ns}$ & $\mathrm{~ns}$ & 0,96 & $-0,91$ & $\mathrm{~ns}$ \\
\hline
\end{tabular}


exploração gesseira, em Pernambuco, Mergulhão (2006) também observou menores quantidades desta proteína quando comparadas às relatadas por Rillig et al. (2001). Em contrapartida, as quantidades de PSRG-T encontradas nesse estudo são superiores às observadas por Silva (2006b) em solos cultivados com maracujá.

Da mesma forma que He et al. (2010) e Rillig et al. (2003), observou-se relação linear positiva entre o carbono orgânico total (COT) e $\mathrm{N}$ do solo e as frações da PSRG (Tabela 8). Este fato pode indicar que as micorrizas arbusculares são, ao longo do tempo, grandes contribuintes para o acúmulo de C no solo (WUEST et al., 2005). As frações do C (ácidos fúlvicos, ácidos húmicos e humina) também estão correlacionadas com as frações da PSRG, à exceção da PSRG-T com os ácidos fúlvicos e da PSRG-FE com a humina. Este padrão pode ser explicado pelo fato da PSRG-T ser uma fração mais estável, ao contrário dos ácidos fúlvicos, que prontamente podem ser hidrolisados, além de apresentarem grande mobilidade dentro do sistema solo (MADARI et al., 2010). Em contrapartida, a PSRG-FE é considerada a fração de PSRG localizada em sítios do solo que são mais susceptíveis à produção e decomposição recentes (LUTGEN et al., 2003), enquanto, a humina se encontra associada à fase mineral do solo e, portanto, é considerada recalcitrante (MADARI et al., 2010). Os teores de $\mathrm{P}, \mathrm{Ca}, \mathrm{K}$ e $\mathrm{Na}$ não apresentaram correlação com a produção de PSRG. Por outro lado, os teores de $\mathrm{Mg}$ e a acidez potencial $(\mathrm{H}+\mathrm{Al})$ foram positivamente correlacionados com a PSRG-FE. Concentrações de PSRG-FE apresentaram correlação negativa com o pH (Tabela 8), tal como observado por Mergulhão (2006).

\section{CONCLUSÕES}

A revegetação da cava de extração de argila influencia no número de esporos e na diversidade de espécies de fungos micorrízicos arbusculares.

A diversidade de esporos de fungos micorrízicos arbusculares no solo aumenta com o reflorestamento da cava, enquanto o número de esporos é reduzido.

O consórcio do eucalipto com a leguminosa promove aumento na diversidade de FMAs, em relação ao monocultivo do eucalipto.

A quantidade de proteína do solo relacionada à glomalina (total e facilmente extraível) aumenta com a revegetação da cava.

\section{REFERÊNCIAS BIBLIOGRÁFICAS}

BATISTA, Q. R. et al. Bioqualidade de área degradada pela extração de argila, revegetada com Eucalyptus spp. e sabiá. Revista Caatinga, Mossoró, v. 22, n.1, p.146-154, jan./mar. 2009.

BEDINI, S. et al. Effects of long-term land use on arbuscular mycorrhizal fungi and glomalinrelated soil protein. Agriculture, Ecosystems \& Environment, Amsterdam, v. 120, n. 2-4, p. 463466, May. 2007.

BIRD, S. B. et al. Spatial heterogeneity of aggregate stability and soil carbon in Semi-Arid rangeland. Environmental Pollution, Essex, v. 116, n. 3, p.445455, mar. 2002.

BRADFORD, M. M. A rapid and sensitive method for the quantification of microgram quantities of protein utilizing the principle of protein-dye binding. Analytical Biochemistry, New York, v. 72, n. 1-2, p. 248-254, May. 1976.

BROWER, J. E.; ZAR, J. H.; ENDE, C. N. von. Field and laboratory methods for general ecology. 3rd ed. Dubuque, $1990.237 \mathrm{p}$.

CAMPOS, H. de. Estatística experimental naoparamétrica. 2. ed. Piracicaba: ESALQ, 1976. 332 p. CAPRONI, A .L. et al. Ocorrência de Fungos Micorrízicos Arbusculares em resíduo da mineração de bauxita revegetado com espécies arbóreas, Acta botanica brasilica, Brasilia, v. 21, p. 99-106, 2007. CAPRONI, A. L. et al. Fungos micorrízicos arbusculares em estéril revegetado com Acacia mangium, após mineração de bauxita. Revista Árvore, Viçosa, v. 29, p. 373-381, 2005

CAPRONI, A. L. Fungos micorrízicos arbusculares em áreas reflorestadas remanescentes da mineração de bauxita em Porto Trombetas/ PA. 2001. 186 f. Tese (Doutorado em Fitotecnia) - Universidade Federal Rural do Rio de Janeiro, Seropédica, 2001.

CAPRONI, A. L. Ocorrência de fungos micorrízicos arbusculares em áreas reflorestadas remanecentes da mineração de bauxita em Porto Trombetas, PA. Pesquisa Agropecuária Brasileira, Brasília, v. 38, n. 12, p.1409-1418. dez. 2003.

CUNHA, L. O. et al. Análise multivariada da vegetação como ferramenta para avaliar a reabilitação de dunas litorâneas mineradas em Mataraca, Paraíba, Brasil. Revista Árvore, Viçosa, v. 27, p. 503-515, 2003.

FOCCHI, S. S. et al Fungos micorrízicos arbusculares em cultivos de citros sob manejo convencional e orgânico. Pesquisa Agropecuária Brasileira, 
Brasília, v. 39, p. 469-476, 2004.

FRANCO, A. A. et al. Uso de leguminosas florestais noduladas e micorrizadas como agentes de recuperação e manutenção da vida do solo: um modelo tecnológico. In: ESTEVES, F. (ed.). Oecologia Brasiliensis: estrutura, funcionamento e manejo de ecossistemas. Rio de Janeiro: UFRJ, 1995. p. 459-467.

GERDERMANN, J. N.; NICOLSON, T. H. Spores of mycorrhizal Endogone species extracted from soil by wet sieving and decanting. Transactions of the British Mycological Society, Cambridge, v. 46, n. 2, p. 235-244, 1963.

GOULD, A. B.; HENDRIX, J. W.; FERRISS, R. S. Relationship of mycorrhizal activity to time following reclamation of surface mine land in western Kentucky - 1: Propagule and spore population densities. Canadian Journal of Botany, Otawa, v. 74, p. 247-261, 1996

GUADARRAMA, P.; ÁLVAREZ-SÂNCHEZ, F. J. Abundance of arbuscular mycorrhizal fungi spores in different environments in a tropical rain forest, Veracruz, Mexico. Mycorrhiza, Berlim, v. 8, p. 267270, 1999.

HE, X.; LI, Y.; ZHAO, L. Dynamics of arbuscular mycorrhizal fungi and glomalina in the rhizosphere of Artemisia ordosica Krasch. In Mu Us sandland, China. Soil Biology \& Biochemistry, Oxford, v. 42, n. 8, p. 1313-1319, 2010.

HENDRIX, W.; GUO, B. Z.; NA, Z. Q. Divergence of mycorrhizal fungal communities in crop production systems. Plant and Soil, The Hague, v. 170, p. 131140. 1995.

KIERMAN, J. M.; HENDRIX, J. W.; MARONEK, D. M. Endomycorrhizal fungi occurring on orphan strip mines in Kentucky. Canadian Journal of Botany, Otawa. v. 61, p. 1798-1803, 1983.

KOSKE, R. E.; GEMMA, J. N. Mycorrhizae and sucession in plantigs of beachgrass in sand dunes. American Journal of Botany, Bronx, v. 84, p. 118130, 1997.

LAVELLE, P.; SPAIN, A.V. Soil ecology. Dordrecht: Kluwer Academic Publishers. 2001. 654 p.

LOSS, A. et al. Atributos químicos do solo e ocorrência de fungos micorrízicos sob áreas de pastagem e sistema agroflorestal, Brasil. Acta Agronómica, Palmira, v. 58, n. 2, p. 91-95, Apr. 2009.

LOVELOCK, C. E.; WRIGHT, S. F.; NICHOLS, $\mathrm{K}$. A. Using glomalin as an indicator for arbuscular mycorrhizal hyphal growth: an example from a tropical rain forest soil. Soil Biology and Biochemistry, Oxford, v. 36, p. 1009-1012, 2004.
LUTGEN, E. R. et. al Seasonality of arbuscular mycorrhizal hyphae and glomalin in a western Montana grassland. Plant and Soil, The Hague, v. 257, p. 71-83, 2003.

MADARI, B. E. et. al. Matéria orgânica dos solos antrópicos da Amazônia (Terra Preta de Indio): suas características e papel na sustentabilidade da fertilidade do solo. Disponível em: $<$ (http://www. biochar.org/joomla/images/stories/Cap_13_Beata. pdf) > Acesso em: 17 de novembro de 2010.

MARINHO, N. F. et al. Respostas de Acacia mangium Willd e Sclerolobium paniculatum Vogel a fungos micorrízicos arbusculares nativos provenientes de áreas degradadas pela mineração de bauxita na Amazônia. Acta Botanica Brasilica, Brasília, v. 18, p. 141-149, 2004.

MEHROTRA, V. S. Arbuscular mycorrhizal associations of plants colonizing coal mine spoil in India. Journal of Agricultural Science, Otawa, v. 130, p. 125-133, 1998.

MELLONI, R.; SIQUEIRA, J. O.; MOREIRA, F. M. S. Fungos micorrízicos arbusculares em solos de áreas de mineração de bauxita em reabilitação. Pesquisa Agropecuária Brasileira, Brasília, v. 38, p. 267-276, 2003.

MENDONÇA, A. V. R. et al. Desempenho de quatro de Eucalyptus spp em plantios puros e consorciados com sabiá (Mimosa caesalpiniaefolia Benth) em cava de extração de argila. Revista Árvore, Viçosa, v. 32, n. 3, p.395-405, maio/jun. 2008.

MERGULHÃO, A. C. E. S. Aspectos ecológicos e moleculares de fungos micorrízicos arbusculares. 152p. 2006. Tese (Doutorado em Ciências Biológicas) - Universidade Federal de Pernambuco, Recife, 2006. MOREIRA, F. M. S.; SIQUEIRA, J. O. Microbiologia e bioquímica do solo. Lavras: UFL, 2002. 625 p.

NICHOLS, K. A.; WRIGHT, S. F. Comparison of glomalin and humic acid in eight native US soils. Soil Science, Baltimore, v. 170, p. 985-997, 2005.

ODUM, E. P. Ecologia. Rio de Janeiro: Guanabara, 1989.

PAULUCIO, V. O. Qualidade química e biológica de área degradada pela extração de argila, revegetada com eucalipto eleguminosas inoculados com micorrizas. 2007. 106 f. Tese (Doutorado em Produção Vegetal) - Universidade Estadual do Norte Fluminense Darcy Ribeiro Campos dos Goytacazes, 2007.

PFLEGER, F. L.; STEWART, E. L.; NOYD, R. $\mathrm{K}$. Role of VAM fungi in mine land revegetation. In: Pfleger, F. L.; Lingerman, R. G. Micorrizae and plant healt, St, Paul: APS Press, 1994. p. 47-82. 
PIELOU, E. C. The measurement of diversity in different types of biological collections. Journal of Theoretical Biology, London, v. 13, p. 131-144, 1966.

PURIN, S. Fungos micorrízicos arbusculares: atividade, diversidade e aspectos funcionais em sistemas de produção de maçã. 2005. Dissertação. (Mestrado em Ciências do Solo) - Universidade do Estado de Santa Catarina, Florianópolis, 2005.

RILLIG, M. C. Arbuscular mycorrhizae, glomalin, and soil aggregation. Canadian Journal of Soil Science, Otawa, v. 84, p. 355-363, 2004.

RILLIG, M. C. et al. (Glomalin, an arbuscularmycorrhizal fungal soil protein, responds to landuse change, Plant and Soil, The Hague, v. 253, p. 293-299, 2003.

RILLIG, M. C. et al. Large contribution of arbuscular mycorrhizal fungi to soil carbon pools in tropical forest soils. Plant and Soil, The Hague, v. 23, p. 167-177, 2001.

RUSEK, J. Biodiversity of Collembola and their functional role in the ecosystem. Biodiversity and Conservation, London, v. 7, p.1207-1219, 1998.

SANTOS, V. L. S. Fungos micorrízicos arbusculares em ecossistema de mata seca no Norte de Minas Gerais. 2010. 68 f.. Dissertação (Mestrado em Fitossanidade e Biotecnologia Aplicada) - Universidade Federal Rural do Rio de Janeiro, Seropédica, 2010.

SCHENCK, N. C.; PEREZ, Y. A manual for identification of vesicular-arbuscular mycorrhizal fungi. 2nd ed. Gainesville: University of Florida, 1988. $241 \mathrm{p}$.

SCHIAVOJ.A., MARTINS, M.A.E.; RODRIGUES, L. A. Crescimento de mudas de Acacia mangium, Sesbania virgata e Eucalytpus camaldulensis, inoculadas com fungos micorrízicos, em casa-devegetação e em cava-de-extração de argila Acta Scientiarum. Agronomy Maringá, v. 32, n. 1, p. 171-178, 2010.

SCHIAVO, J. A. Revegetação de áreas degradadas pela extração de argila, com espécies micorrizadas de Acacia mangium, sesbania virgata e Eucalyptus camaldulensis. 2005. 117 p.Tese. (Doutorado em Produção Vegetal) - Universidade Estadual do Norte Fluminense Darcy Ribeiro Campos dos Goytacazes, 2005.

SILVA, C. F. Atributos químicos e biológicos em cavas de extração de argila revegetadas com eucalipto e leguminosas. 2009. $172 \mathrm{f}$. Tese. (Doutorado em Produção Vegetal) - Universidade Estadual do Norte Fluminense Darcy Ribeiro,
Campos dos Goytacazes, 2009.

SILVA, C. F. et al. Atividade de fungos micorrízicos arbusculares em dunas litorâneas impactadas por mineração. In: REUNIÃO BRASILEIRA DE FERTILIDADE DO SOLO E NUTRIÇÃO DE PLANTAS, 29; REUNIÃO BRASILEIRA SOBRE MICORRIZAS, 13.; SIMPÓSIO BRASILEIRO DE MICROBIOLOGIA DO SOLO, 11; REUNIÃO BRASILEIRA DE BIOLOGIA DO SOLO, 8., 2010, Guarapari. Fontes de nutrientes e produção agrícola: modelando o futuro: Anais... Viçosa: Sociedade Brasileira de Ciência do Solo, 2010.

SILVA, C. F. et al. Fungos Micorrízicos Arbusculares em áreas no entorno do Parque Estadual da Serra do Mar Em Ubatuba (SP). Revista Caatinga, v. 19, p. 1-10, 2006.

SILVA, L. X. et al. Fungos micorrízicos arbusculares em áreas de plantio de leucena e sábia no estado de Pernambuco. Revista Árvore, Viçosa, v. 31, p. 427 435, 2007.

SILVA, R. F. et al. Comunidade de fungos micorrízicos arbusculares em solo cultivado com eucalipto, pinus e campo nativo em solo arenoso, São Francisco de Assis, RS. Ciência Florestal, Santa Maria, v. 18, n. 3, p. 353-361, jul-set., 2008.

SNEDECOR, W.; COCHRAN, W. G. Statistical methods. $8^{\text {th }}$ ed. Ames: Iowa State University Press, 1989. $502 \mathrm{p}$.

SOUZA, G.. I. A. et al. Arbuscular Mycorrhizal fungi in agricultural and forest systems. Global Science and Technology, Rio Verde, v. 3, n. 2, p. 1-9, maio/ ago. 2010.

SYLVIA, D. M.; JARSFER, A. G. Shearedroot inocula of vesicular-arbuscular mycorrhizal fungi. Applied Environmental Microbiology, Washington, v. 58, p. 229-232, 1992.

WRIGHT, S. F.; UPADHYAYA, A. A. A survey of soils for aggregate stability and glomalin, a glycoprotein produced by hyphae of arbuscular mycorrhizal fungi. Plant and Soil, The Hague, v. 198, p. 97-107, 1998.

WRIGHT, S.; UPADHYAYA, A. A.. Extraction of an abundant and unusual protein from soil and comparison with hyphal protein of arbuscular mycorrhizal fungi. Soil Science, Baltimore, v. 161, p. 575-586, 1996.

WUEST, S. et al. Organic matter addition, N, and residue burning effects on infiltration biological and physical properties of na intensively tilled siltloam soil. Soil and Tillage Research, Amsterdam , v. 84, p. 154-167, 2005. 